\title{
Egress from a Hospital Ward During Fire Emergency
}

\author{
Annunziata D’Orazio ${ }^{1 *}$, Luca Grossi ${ }^{1}$, Davide Ursetta ${ }^{1}$, Grazia Carbotti ${ }^{2}$, Leo Poggi ${ }^{2}$ \\ ${ }^{1}$ Dipartimento di Ingegneria Astronautica, Elettrica ed Energetica, Sapienza University of Rome, Via Eudossiana 18, Roma \\ 00184, Italy \\ ${ }^{2}$ Campus Bio-Medico University Hospital of Rome, Via Alvaro del Portillo 200, Roma 00128, Italy
}

Corresponding Author Email: annunziata.dorazio@uniroma1.it

https://doi.org/10.18280/ijsse.100101

Received: 10 July 2019

Accepted: 1 November 2019

\section{Keywords:}

fire safety engineering, healthcare buildings, hospital evacuation, evacuation simulator, egress time, smoke proof filter, bottleneck elements

\begin{abstract}
There are many issues in a hospital evacuation, related both to conditions of the patients and to building complexity. Moreover, as consequences of fire, there may be delays in surgeries and medical diagnosis, or interruption in treatment for both inpatient and outpatient. This work identifies and assesses problems that arise in the egress from the ward located at third floor of the Campus Bio-Medico University Hospital of Rome, using a simulation software. Moreover, we perform a comparison between simulation results and experimental results by means of a real fire drill. We have considered a maximum of 116 people in the ward to its maximum capacity. We have created three different fire scenarios: fire in the electrical room, in the kitchen room and in a patient room. The time needed to evacuate fully the ward was far behind the fire resistance time of the structures. More than that, there was an overcrowded area in the ward that acted as a bottleneck: the so-called "smoke proof filter"; this area is intended to separates the two near wards and, although built according to the Italian fire department regulation, it holds back people and beds.
\end{abstract}

\section{INTRODUCTION}

The study of building evacuation began at the start of the 20 th century [1-3]. At the end of the 20th century, the interpretation of the fire safety of buildings changed from a technological to a more behavioural perspective [4-7]. The reader can find a review, about connection between fire and human behaviour [8]. Modern fire protection engineering methods require more advanced software to perform complex analysis and of Serious Games to train the professionals' behaviour [9-11]. Fire and evacuation simulators are powerful computer modelling tools that can be used to provide answers to questions that more traditional analysis approaches might not give. Fires are not predictable, so the decision to evacuate must often be made very quickly, while with tornados, hurricanes, and flooding the decision teams have time prior to the event to make evacuations decisions. Many factors affect evacuation time in a hospital [12-15]: the number of patients, the mix of patient acuity, the available staff, the available exit routes within the hospital, the patient transportation requirements, the available transportation resources (vehicles and the necessary accompanying staff, equipment and supplies), the entry or egress points at the hospital and the location of receiving care sites. The major incidents are unpredictable and each will present a unique set of challenges. Deciding whether preventively evacuate or shelter-in-place, requires consideration of many factors: the nature of the event, including the magnitude and the area of impact, how long a hospital can shelter-in-place in case of damaged critical infrastructures. There are many issues be considered in a hospital evacuation, related both to patient's conditions and to building complexity.

\subsection{Number of patients and patient acuity mix}

The risk of moving medically unstable patients are high, and physicians and decision teams must weigh the risks of moving these patients from the threatened ward to another hospital against the risks of moving them in another ward. Medically unstable patients are particularly resource-intensive and it may be necessary to transfer them with several healthcare professionals (to provide manual ventilation, monitor cardiac status etc.). The total number of patients who need assistance to evacuate safely will typically be substantially fewer than the total patient census. Some patients will be medically stable and likely they will be able to go out alone or with family members. Other patients will be ambulatory patients and will be able to walk out of the hospital only with assistance, while still others will require wheelchairs. Some will require sophisticated equipment and handling if they are to survive the evacuation, and a few very ill patients will be unlikely to survive if moved. Transportation resources include not only the vehicle, but also the required accompanying staff, equipment, and supplies.

\subsection{Available staff}

Hospitals also typically have significantly fewer staff on hand during night and weekend shifts, which would greatly affect the ability to move patients quickly out of the hospital in an urgent evacuation. Some hospitals rely more heavily than others do on staff from temporary agencies, or on temporary staff recruited for short assignments (especially nurses and technicians). Such staff may not be as readily available as fulltime hospital employees do during an emergency. Volunteers, visitors, and family members may be available to assist in evacuating some patients. Volunteers must be assigned 
appropriate tasks, as trained medical staff are required to move and transport most patients with intensive care needs. The evacuation process drastically reduces the number of staff available to stay in the hospital and care for patients, as some staff must join transport team. The staff must move patients out of the hospital and, if necessary, assist them during the transport to a receiving care site. Depending on the type of disaster, there will likely be staff shortages. It is helpful to try to pre-estimate the attrition rate of a hospital's workforce during a disaster, as many employees may themselves become victims of the disaster, or may have family responsibilities that interfere with their ability to staff the hospital (e.g. evacuating dependent children).

\subsection{Available egress routes from within the hospital}

While unlikely to be a problem during an "orderly and planned" evacuation, egress from a hospital may be severely constrained during a "drop everything and go" evacuation. Stairwells or exits may be obscured by smoke or unavailable because of fire. Stairwells may be dark if backup power has failed. Elevators can also be out of service, lengthening the time required to move all patients out of the hospital. For instance, because elevators were not operating, patients at Memorial Hermann Hospital in Houston, Texas, were carried down 10 flights of stairs on backboards without overhead lighting or air-conditioning. Up to five infants were secured to one backboard. Several adults were needed to carry out each adult patient. Evacuation was temporarily halted when staff and volunteers were exhausted, to avoid injuries. In an orderly and planned evacuation, there is time to move patients in a manner that maximizes safety for all patients and staff. In a "drop everything and go" evacuation, instead, patients and staff are in immediate danger and must exit the unit and/or hospital as quickly as possible. In this case, optimal procedures for safely moving patients may be abandoned in favour of the fastest possible egress.

Having in mind all these considerations, we developed a model and assessed the effectiveness of the software predictions by comparing the simulation results with the outcome of a real evacuation drill. We decided to model the egress from the ward located at third floor of the Campus BioMedico University Hospital of Rome, using Pathfinder (featured by Thunderhead Engineering).

\section{SIMULATION MODELS FOR EVACUATION}

To deepen the study and analysis of evacuation, it is crucial the use of the so-called automatic models, which allow to process a considerable amount of variables. In particular, the automatic models allow simulating at the same time the behaviour of several hundreds of persons that act and interact in a different way from each other [11, 16]. Simulation processes can be based on genetic algorithms and game theory $[17,18]$. Among the features, that can be taken into account through a simulation model of the exodus, the most important are the following. The counter-current flow, the manual lock of the outputs or the presence of obstacles, the behaviour modification as a result of the fire, the definition of groups, the presence of people with limited capabilities, the delay or premovement times, the use of elevators, the choice of routes by the people involved, impatience or automatic behaviours. In general, the simulation models differ from each other by the weight of the behaviour in the overall calculation, and they are classified, according such weight as motion models, partially behavioural models and behavioural models.

\subsection{Motion models}

To overcome the limits of the flow models, which treat the people as a fluid, have been developed model of movement, which focus on the movement of people from one point to another, into the building. The main results of these models include the time of exodus, the identification of bottlenecks and the evaluation of the flow through the openings. In some cases, the models provide for the possibility that not all people move along the shortest path, but that they are distributed to achieve the density that produces the exodus in the shortest time. In the absence of this technique, the movement patterns follow the criterion of moving people along the little space as possible. Most of the motion models uses a coarse grid, made up of nodes (the local) and arcs (the distance between the midpoints of the nodes). Also, the description of the evacuations, which usually is global, implies that people are considered as a homogeneous group of individuals, that possess the same knowledge and the same capabilities of movement and that, therefore, they move up to the exit in the fastest way. Precisely this hypothesis, which does not consider the differences due to the behaviour of the people, shows that the law that governs the movement in most of the models is that of the correlation between speed and density.

\subsection{Partial behavioural models}

The models known as partial behavioural models, serve to introduce in the calculation some details, which distinguish the individual persons not only on the base of their speed, but also on the response to the environment in which they act. This interaction allows to taking into account the time of premovement (distributed among the people present), the difficulties of the movement, the overtaking and the effect of smoke and heat. The description of the building in which the simulation takes place, is made through the simultaneous use of a coarse grid and continuous networks. Most of these models is based on the law of correlation between speed and density to calculate the movement of people. The visualization of the building is more sophisticated and, in some cases, can use the CAD data for the description of the building. Compared with behavioural models, they introduce differences among people in physical terms (body size, delay in movement, etc.) rather than cognitively.

\subsection{Behavioural models}

The behavioural models, compared to the previous ones, take into account the decisions and behaviour of the individual persons, in addition to the motion toward the exit. The rules of behaviour, according to which people move (for example, if a person sees smoke in the stairwell will not enter and will try another outlet), are defined in each model. The simulation environment is given normally with refined mesh. Almost all of the behavioural models have the option to assign probabilities to the activities carried out by each action according to probability of occurrence. These models are also able to use the data on the evolution of the fire and provide a visualization of the structure through the $\mathrm{CAD}$ data. 


\section{THE SOFTWARE}

The current availability of the market is many and varied, so it can meet the different needs [19]. The software used in this work is Pathfinder. It is a simulation program consisting of three main elements: a graphical interface, a simulator and a 3-D viewer of the results. The movement of the occupants can be modelled in two ways: SFPE mode and Steering mode. The first method implements the concepts present in the "SFPE Handbook of Fire Protection Engineering" [20], i.e. it uses the model of flow in which the speeds of pedestrians are function of the density of occupants within each room and the flow of people through the doors is controlled by the width of the doors themselves. The Steering mode provides a more realistic model of the behaviour, compared to the previous mode, because it eliminates the calculations based on the density of the occupants and the behaviour of individuals is modelled in a way that avoids collisions. The tails of occupants at the doors (bottlenecks) are not explicitly considered, although it is inevitable that they can occur [21]. In Pathfinder, the geometry of the buildings is represented by triangular meshes. The areas that cannot be walked, as walls and furniture, are simulated by empty spaces within the mesh. For each occupant, a position is defined in space, together with a profile (that specifies the size, the speed etc.) and a behaviour, that defines actions and goals. The occupants are modelled on the mesh by cylinders.

\section{THE CASE STUDY}

We decided to model the egress from the ward located at third floor of the Campus Bio-Medico University Hospital of Rome of Rome, using Pathfinder (featured by Thunderhead Engineering). We focused on just one ward because in Italy is preferred a shelter-in-place, for buildings such as hospital, which are designed to be fire resistant for at least 120 minutes. A time of two hours is considered more than enough for fire brigades to come, evacuate the whole building and try to extinguish the fire. An "interim plan" was available, designed to bring patient to a location (in most cases the next ward) where they could then be carried out and loaded into vehicles more quickly - in effect a two-stage evacuation. Moreover, we wanted to compare the simulation with a real fire drill. Bearing in mind that a hospital evacuation have to be planned differently depending on weather the entire area is being evacuated or just one ward, we knew that we just could not run a fire drill in the whole hospital (working at its full capability); that is why we focused on the evacuation of a single ward. We supposed that the evacuation should be conducted as quickly as possible, so the most mobile patient should be evacuated first. Fire and evacuation modelling are essential to assess the hazards associated to detailed fire scenarios. At a practical level, we focused to estimate some data of interest (e.g. evacuation time), having some others interesting findings from all the graphs and plots that Pathfinder provided. A plan view of the ward space is presented in Figure 1, which shows the compartments of the ward space. The red solid lines represent continuous walls and fire doors REI 120 (i.e. that maintain mechanical strength airtightness and thermal insulation for 120 minutes), and the red dotted lines represent continuous walls and fire doors REI 30. The gray zones identify smoke proof filters. The "E" letter shows the presence at that point of a fire extinguisher, and the arrows indicate the possible escape routes. The department consists of the following environments: 21 patient rooms (of which 2 are dedicated to the Day Hospital), equipment storage, clean storage and dirty storage, nurses' room, ward sister room, 5 rooms dedicated to medical staff, kitchen, waiting room, cleaning room, electrical room, 26 toilets. The patients admitted to the third level on the west side can be geriatrics, of plastic surgery, urology and otolaryngology. The age and condition of the patients within the ward are extremely variable and this implies, for the purposes of fire safety, greater complexity in the drafting of an emergency plan that effectively considers all aspects of the ward. Very important is to identify in advance the areas with greatest fire hazards, in order to determine appropriate emergency strategies. Starting from a heuristic evaluation, the possible causes of fire within the ward could be numerous and including the following. The malfunction of electrical equipment may lead to the development of short circuits. The presence of highly flammable material, within environments dedicated to the storage, the leaks of gas, not readily identified, in the distribution network of medical gases, can cause fire. The malfunction of equipment at the service of air conditioning and ventilation plants, the poor maintenance of plants and equipments, bad behaviours by the occupants (e.g. smoking within the ward) can cause fire. In addition, a fire can also be arson or may be caused intentionally, for example, where there are waste, in places rarely visited or dedicated to temporary storage, etc. In the scenarios discussed in this work, we assumed that the stage of ignition of the fire is caused by problems of electrical type. In the first scenario, we have considered a short circuit in the electrical room. In the second scenario, we have assumed a short circuit on the stove used in kitchen room. In the third scenario, fire is assumed to start in a patient room.

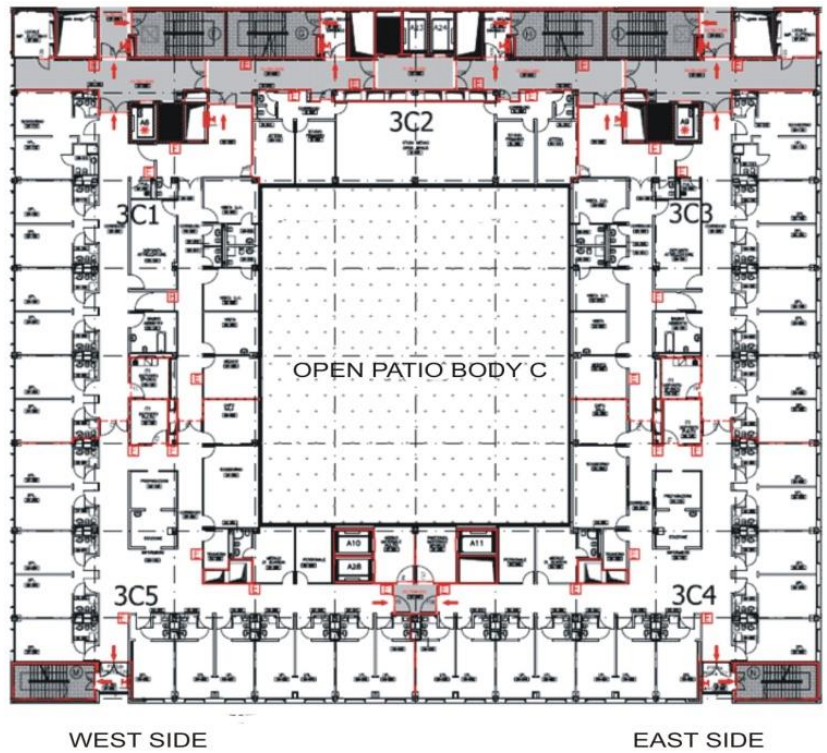

Figure 1. Plan view of the two hospital wards: 3 East and 3 West; the space is made up of many rooms connected by a corridor

The ward consists of many rooms connected by a corridor. Table 1 reports in detail the area of each room. The real floor space on which occupants can walk was created importing the DWG file. Then we set all the obstructions in each room of the ward (beds, furniture, and control desk) as holes in the floor and added the doors (between two room or a room and a 
hallway) and the exits (the fire safety exits) to the model, so that every room was connected and no door or other connection was missing. In the simulation, we made the distinction between the output used to move from one room to another, called "doors", and the doors used as emergency exits that lead to a safe place, called "exit". Each output can be set in open or closed configuration, a specific preferred crossing direction can be chosen and a flow rate of occupants, measured as persons per second, can be defined. In the model, based on the fire scenarios, we have inserted occupants who take part in the evacuation simulation. Table 2 reports the values of crowding (in terms of number of people per square meter) within the different environments. Once the base model was completed, its geometric elements and data inputs were authenticated to be error free, and then exported in order to run the simulation. A survey was performed in the ward during $2 / 3$ days, in order to assess the medium number of staff (doctors, nurses, others) and the number and type of patients that ordinarily can be found; results are shown in Table 3 . Visitors can enter the ward from 15.00 to 19.00 o'clock, rocketing the maximum number of occupants in the ward up to 116 people. During the night shift instead, the number of staff and the total number of people in the ward reaches its minimum, because no visitor is allowed to enter the ward and there are just four nurses attending a maximum of 37 patient, as reported in Table 4.

Table 1. Rooms area in the ward

\begin{tabular}{cccc}
\hline Room & Area $\left(\mathbf{m}^{2}\right)$ & Room & Area $\left.\mathbf{~ m}^{\mathbf{2}}\right)$ \\
\hline Two beds rooms & 26 & Warehouse & 22 \\
\hline $\begin{array}{c}\text { Single bed } \\
\text { rooms }\end{array}$ & 12 & $\begin{array}{c}\text { Clean } \\
\text { material dept }\end{array}$ & 8 \\
\hline $\begin{array}{c}\text { Outpatient room } \\
\text { Medical staff } \\
\text { room }\end{array}$ & 11 & $\begin{array}{c}\text { Dirty material } \\
\text { dept }\end{array}$ & 7 \\
\hline Nurse room & 12 & Sluice & 2.5 \\
\hline $\begin{array}{c}\text { Nurses station } \\
\text { Night-watch } \\
\text { room }\end{array}$ & 22 & $\begin{array}{c}\text { Power control } \\
\text { board }\end{array}$ & 11 \\
\hline Staff room & 11 & Toilet & 1.4 \\
\hline $\begin{array}{c}\text { Cooking } \\
\text { facilities room }\end{array}$ & 5 & $\begin{array}{c}\text { Handicap } \\
\text { bathroom }\end{array}$ & 11 \\
\hline & & $\begin{array}{c}\text { Two beds } \\
\text { rooms }\end{array}$ & 26 \\
\hline
\end{tabular}

Table 2. Crowding density in the ward

\begin{tabular}{cc}
\hline Environment type & $\begin{array}{c}\text { Crowding density (number of } \\
\text { people per square meter) }\end{array}$ \\
\hline Inpatient room & 0.31 \\
\hline Inpatient room suite & 0.075 \\
\hline $\begin{array}{c}\text { Day Hospital } \\
\text { inpatient room }\end{array}$ & 0.17 \\
\hline Medical staff & 0.47 \\
\hline Ward sister room & 0.084 \\
\hline Nurses room & 0.32 \\
\hline Room of the night & 0.087 \\
\hline shift & 0.23 \\
\hline Staff & 0.42 \\
\hline Kitchen & 0.044 \\
\hline Equipment storage & 0.12 \\
\hline Clean storage & 0.14 \\
\hline Dirty storage & 0.40 \\
\hline Cleaning room & 0.13 \\
\hline Waiting room &
\end{tabular}

Table 3. People in the ward

\begin{tabular}{|c|c|c|c|c|}
\hline \multirow{2}{*}{ Job } & \multirow{2}{*}{$\begin{array}{c}\text { Fire } \\
\text { marshals }\end{array}$} & \multicolumn{3}{|c|}{ Shift } \\
\hline & & day & afternoon & night \\
\hline Nurses & 5 & 4 & 4 & 3 \\
\hline Nurses students & - & 4 & 4 & - \\
\hline Paramedics & - & 2 & 2 & - \\
\hline $\begin{array}{l}\text { Medical students } \\
\text { and } \mathrm{PhD}\end{array}$ & - & 10 & 10 & 1 \\
\hline Cleaning Staff & - & 1 & - & - \\
\hline Waitress & - & 1 & - & - \\
\hline Visitors & - & - & 74 & - \\
\hline
\end{tabular}

Table 4. Characteristics of the patients

\begin{tabular}{cc}
\hline Total number & 37 \\
\hline Number of men & 19 \\
\hline Number of women & 18 \\
\hline Men's age range & $19-91$ \\
\hline Women's age range & $22-99$ \\
\hline Bed-bound & 10 \\
\hline Disabled & 6 \\
\hline Dysfunctions & $\begin{array}{c}\text { Breathing difficulties, cardiac } \\
\text { disease, late chronic dysfunction, } \\
\text { low weight syndrome, late acute } \\
\text { dysfunction, lower urinary tract } \\
\text { symptoms, prostate dysfunction, etc. }\end{array}$ \\
\hline
\end{tabular}

Each occupant has been defined by a profile (e.g. nurse, fire fighter, geriatric inpatient) and a behaviour (e.g. wait in the room until the fire alarm rings, go to a patient room, go to an exit). Table 5 reports the profiles of the occupants of the analysed ward. They are geriatric patient (able to move without assistance, bed-bound or needing assistance), plastic surgery patient (able to move without assistance, bed-bound or needing assistance), otolaryngology patient (able to move without assistance or needing assistance), urology patient (able to move without assistance or needing assistance), nurse, nurse student, doctor, medical student, paramedic, maintenance staff, waitress, fire fighter, visitor.

Even if each profile can be described by many parameters, we decided to use only five of them, keeping the others (such as acceleration time, slow factor etc.) at their default value, since very few data are to date available in the literature.

A simulation of evacuation strictly holds only for a specific scenario and it is hardly possible to extend the results to different scenarios; on the other hand, to implement a very detailed simulation could be counterproductive, and the obtained data could be questioned. The variables selected in our case are the speed, the width of shoulders, the preference of the outputs, the reduction factor (a measure of the volume reduction allowed to each occupant, for example through a bottleneck) and the comfort distance. As for the speed parameter, values for disable and elderly people have been found in literature; for people to be mobilized with bed, the value has been determined by testing the real egress of a bed (with a patient lying in it) in an empty ward, finding out its average speed. People are simulated as cylinders, as shown in Figure 2 (a), with diameter equal to the shoulder width; the shoulder width parameter has been set equal to $40-48 \mathrm{~cm}$ for women and $45-50 \mathrm{~cm}$ for men. The beds have been approximated as a cylinder with the maximum allowable shoulder width $(77 \mathrm{~cm})$ and a comfort distance of $1.73 \mathrm{~m}$, so that the overall length is $220 \mathrm{~cm}$, as shown in Figure 2 (b); however, this larger comfort distance is not well rendered in the simulation, because bed-bound patients stay close to other patients. 
Table 5. Profile parameters

\begin{tabular}{ccccc}
\hline Mobility feature & Profile & Speed $\mathbf{( m / s )}$ & Shoulder width $(\mathbf{c m})$ & Current door preference (\%) \\
\hline Able without assistance & Geriatric patient 1 & $0.6-0.8$ & $42-48$ & 100 \\
\hline Mobilized with bed & Geriatric patient 2 & $0.25-0.40$ & 77 & 100 \\
\hline Need of assistance & Geriatric patient 3 & $0.21-0.40$ & $42-48$ & 100 \\
\hline Able without assistance & Plastic surgery patient 1 & 1.10 & 45 & 100 \\
\hline Mobilized with bed & Plastic surgery patient 2 & 0.34 & 77 & 100 \\
\hline Need of assistance & Plastic surgery patient 3 & 0.40 & 45 & 100 \\
\hline Able without assistance & otolaryngology patient 1 & $1.10-1.40$ & $42-48$ & 100 \\
\hline Need of assistance & Otolaryngology patient 2 & 0.50 & 43 & 100 \\
\hline Able without assistance & Urology patient 1 & 1.30 & 45 & 100 \\
\hline Mobilized with bed & Urology patient 2 & 0.34 & 77 & 90 \\
\hline Able without assistance & Nurse & $1.10-1.60$ & $42-46$ & 80 \\
\hline Able without assistance & Nurse student & $1.10-1.60$ & $42-48$ & 90 \\
\hline Able without assistance & Doctor & $1.10-1.60$ & $42-48$ & 80 \\
\hline Able without assistance & Medicine student & $1.10-1.60$ & $42-48$ & 90 \\
\hline Able without assistance & Paramedic & $1.10-1.60$ & $43-45$ & 20 \\
\hline Able without assistance & Cleaning staff & 1.00 & 45 & 20 \\
\hline Able without assistance & Maintenance staff & $1.10-1.60$ & $44-47$ & 20 \\
\hline Able without assistance & Waitress & 1.00 & 77 & 20 \\
\hline Able without assistance & Fire fighter & $1.30-1.70$ & $45-50$ & 10 \\
\hline Able without assistance & Visitor & $1.00-1.60$ & $40-48$ & \\
\hline
\end{tabular}

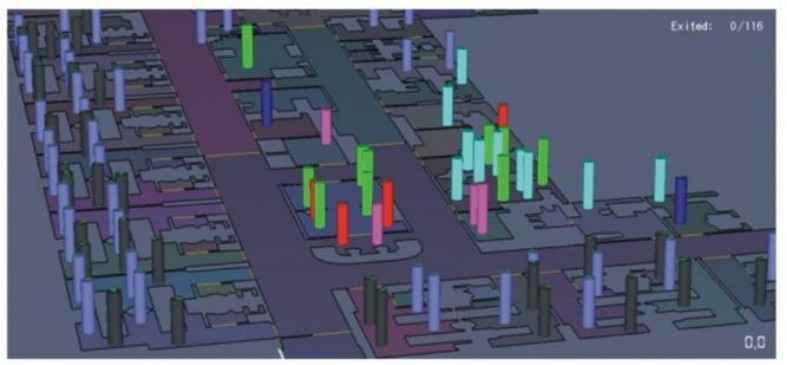

(a)

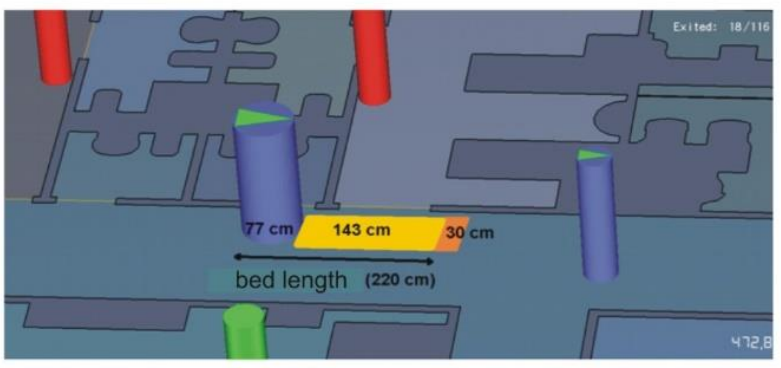

(b)

Figure 2. (a) People as cylinders: each colour identifies a different profile. (b) Bed length

To take into account a bed that moves through a door, the door's state has been set as open or closed for a certain amount of time. Nurses are supposed to move the beds across the ward; this action (two people walking together) is not available in Pathfinder so that it has been simulated with a nurse in the patient room, waiting until bed-bound patient exits the ward. Current door parameter says if the occupant can freely switch the door exit $(0 \%)$ or if is forced toward a certain exit $(100 \%$, especially for bed-bound patients). We assigned a wide range of values to this parameter, from $10 \%$ of the visitors, who are able to egress from whatever exit they choose, to $100 \%$ of the bound-bed patient, who can only egress from the exit toward the next ward or toward the hallway (minimum route). The reduction factor specifies how well an occupant may squeeze past others in tight corridors. In a hospital ward, nurses help inpatients and visitors to reach the exits safely, so we set a value of zero for visitors and patients, and one for nurses and staff, supposing that they can "squeeze" themselves in order to go back and assist someone else. The comfort distance parameter specifies the desired distance one occupant will try to maintain with others nearby. We choose different ranges of values for this parameter, as shown in Table 5. For a bedbound patient, for instance, we set a value of 1.73 , in order to simulate the bed's length, while we considered that nurses and doctors needed a lower value $(0.15 \neg 0.20)$. To create a profile, all parameters previously described can be set not only as simple constant values but also expressed in terms of distribution (uniform, normal and lognormal). While the profile is the same for every scenario, the behaviour changes, due to the sequence of actions that a person should perform. For instance, Table 6 reports the behaviour of a nurse in the fire in the electrical room scenario, in terms of actions allowed. The actions allowed by the software are A (go to a place), B (go to a room), C (wait) and D (use elevator). The action D has not been considered, since the simulations relate to the same floor. Initial delay time is a very important parameter: it specifies the time passed before the occupant moves, from its starting position to an emergency exit, or he makes the next action. Many papers discuss about the value to assign to this variable. In all our scenarios, the initial delay of the patients is the time needed to the nurse to reach the patient's room; with regard to the visitors, emotionally linked to the patients, the delay time corresponds to the time needed to the patient to leave the room.

Table 6. Behaviour of nurse 1 in the fire in the electrical room scenario

\begin{tabular}{cc}
\hline Nurse 1 & 110 \\
\hline Initial delay (s) & $\mathrm{F} 30$ \\
\hline Exit & $\mathrm{A}+\mathrm{C}+\mathrm{B}+\mathrm{C}+\mathrm{B}+\mathrm{C}+\mathrm{B}+\mathrm{C}+\mathrm{B}+\mathrm{C}$ \\
\hline Actions order & $\begin{array}{c}\text { Nurse 1 smells burnt, alerts } \\
\text { another nurse and tries to } \\
\text { extinguish the fire, while nurse } \\
\text { 2 alerts the Control Room }\end{array}$ \\
\hline $\begin{array}{c}\text { Bumber of people with } \\
\text { the same behavior }\end{array}$ & 1 \\
\hline
\end{tabular}




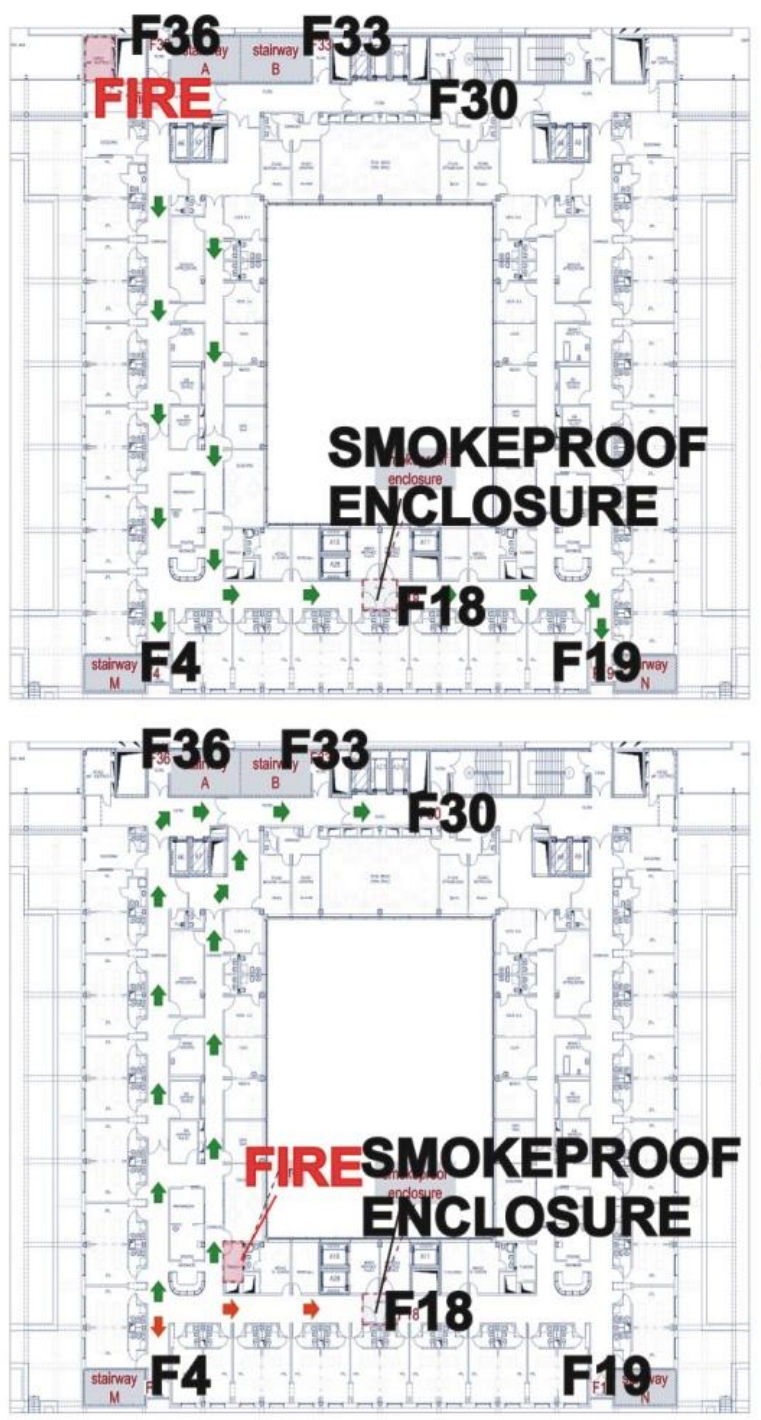

(a)

(b)

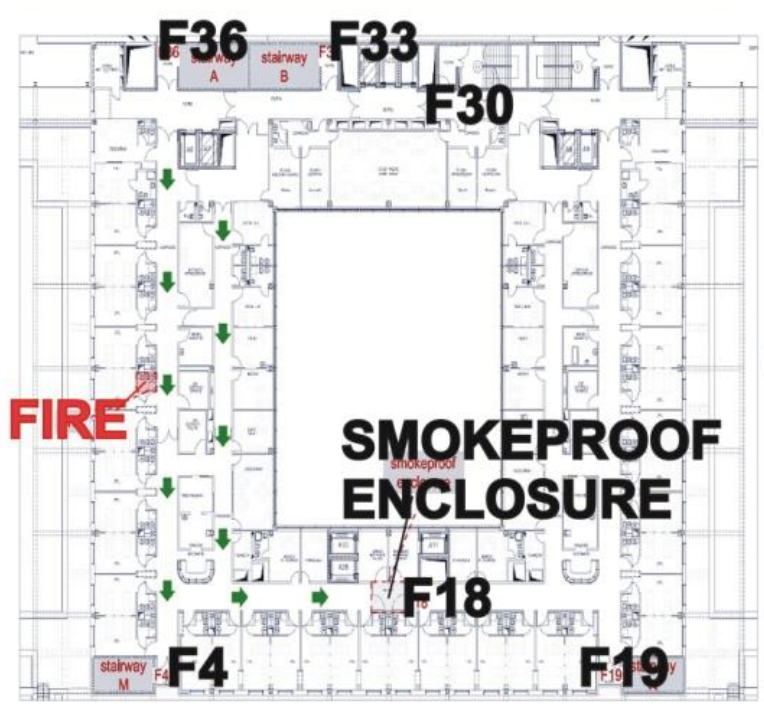

(c)

Figure 3. Ward of Figure 1: fire in (a) electrical room, (b) kitchen room, (c) patient's room

The first supposed scenario is a fire in the electrical room, as shown in Figure 3a. In this scenario, fire exits A and B are not available since they are too close to the fire. Visitors are forced to use exits $\mathrm{M}$ and $\mathrm{N}$ and reach the basement of the building while patients enter the next ward through the exit F18. In fact, available exits are F4, F18 and F19. The area near exit F18 separates one ward from the other, its structures are fire/smoke/heath resistant for 120 minutes and it is designed so that smoke cannot spread from one ward to the other, having vents on the top or being forced ventilated. However, unfortunately, egress can occur both ways, from one ward to the other and back. That is why one door opens facilitating the egress and the other preventing it, according to Italian's fire protection laws $[22,23]$. The second supposed scenario is a fire in the kitchen room, as shown in Figure 3b. The kitchen room is located in the middle of the ward so in this case the smoke is supposed to spread in the corridor so that some exit area is no longer available after a certain amount of time. Since the most dangerous zone is in the middle of the ward, the egress will start from the rooms closest to the fire, whether or not patients need assistance to move. Exits F4 and F18 can be used for few minutes only and just by the nearby rooms (orange pathway), while all other patient should use exits F36, F33 and bed-bound patients can reach the next ward using exit F30. The third supposed scenario is a fire in the patient's room, as shown in Figure 3c. This scenario has been used to perform a simulation, which was the same as the real drill exactly (identical number of persons, identical sequence of actions, identical available exits). The available exits are F18 and F19.

Table 7 summarizes the differences between the three supposed scenarios in terms of people involved and exits used.

Table 7. People involved and exits used in each scenario

\begin{tabular}{ccc}
\hline Scenario & $\begin{array}{c}\text { Number of } \\
\text { people }\end{array}$ & Available exits \\
\hline Fire in the electrical room & 116 & F18, F4, F19 \\
\hline Fire in the kitchen room & 116 & $\begin{array}{c}\text { F4, F8 (for few } \\
\text { minutes), F36, } \\
\text { F33 }\end{array}$ \\
\hline Fire in the patient room & 76 & F18, F19 \\
\hline
\end{tabular}

\section{SIMULATION RESULTS}

With regard to the egress time, results were almost the same for scenarios regarding fire in electrical and kitchen room. In the first case, shown in Figure 4a, 1800 seconds are necessary to empty the ward; in second case, shown in Figure $4 \mathrm{~b}$, the egress time is equal to 1370 seconds. From the figure, one can see that for the first period (1360 seconds and 970 seconds respectively) nobody exits the ward. It takes a certain amount of time for people to move, because the fire needs to be detected and notified, the fire alarm needs to be propagated and the staff needs to organize the evacuation of the patients [24-28]. This "pre-evacuation time" decreases if people are aware of what they are supposed to do in case of fire (if more fire drills are conducted in the ward, for instance), if the firefighting system and the fire alarm system are efficient and if they are working well. The total time for evacuation considers the detection and notification time, the premovement time (including response and recognition time), the movement time (queuing time and travel time). After a peak in the evacuation of the ward, a flat can be found in the graphs of both scenarios, because the patients with no need of assistance move first, while it takes longer to move the last bed-bound patients. Evacuation time for the third scenario was 957 seconds. In this scenario (shown in Figure 4c the total number of evacuated people was lower (76 instead of 116) and bed-bound patients were 6 instead of 10 (supposed in the other two scenarios). As for the first and second scenarios, a high flow rate occurs through the exit F18. For the first scenario, 
shown in Figure 5a, this exit is the only opening for the patient to pass to the contiguous ward. In the second scenario, shown in Figure 5b, this exit is used for a short time, since it is very near to the kitchen room. Figure $5 \mathrm{c}$ reports the third scenario. The maximum flow rate through the exit F18 is equal to 0.51 persons/s.

In order to evaluate the formation of queues near to the exit F18, it is useful the graph representing the number of occupants, as a function of the time, into the smoke proof filter placed between contiguous wards and preceding the exit F18. Figure 6a shows the number of persons in the small area in front of exit F18 in the first scenario.

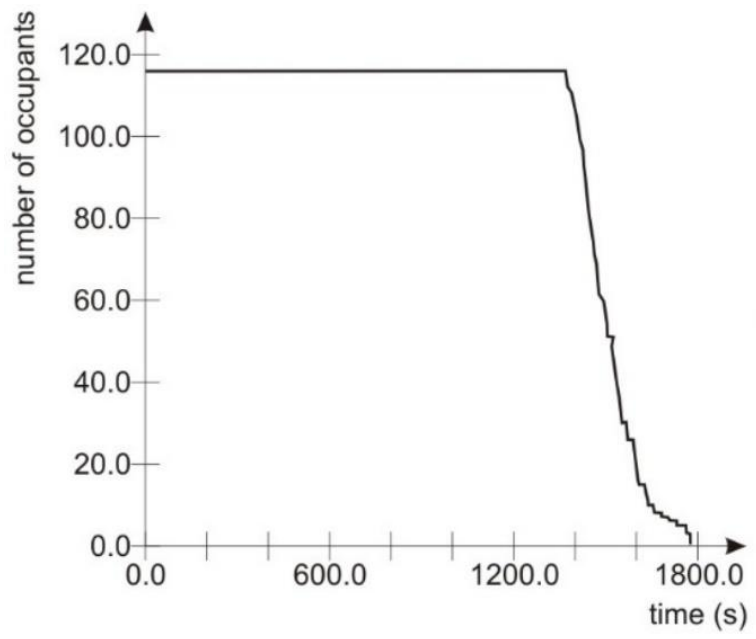

(a)
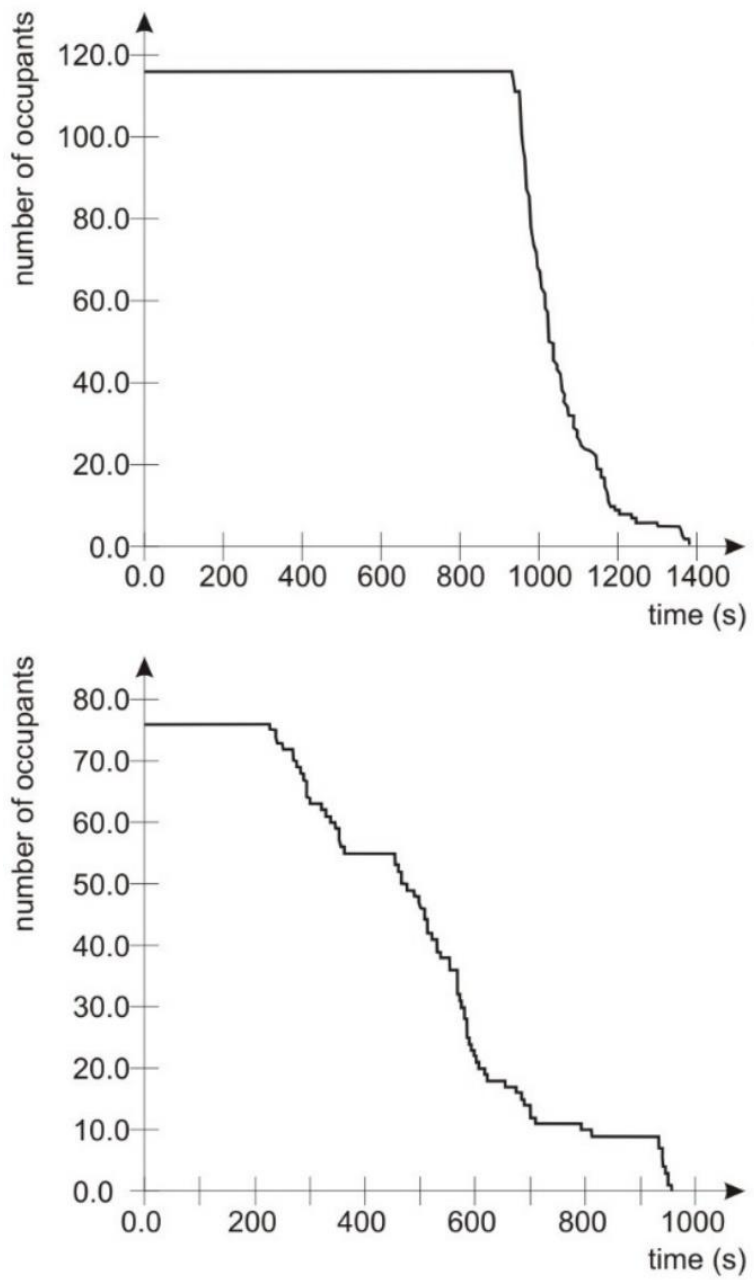

Figure 4. People in the ward over time: fire in (a) electrical room, (b) kitchen room, (c) patient room

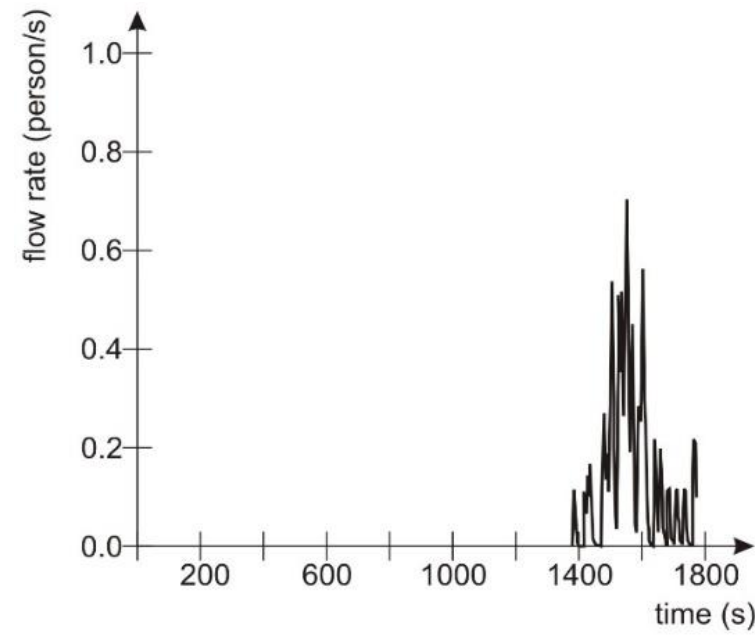

(a)

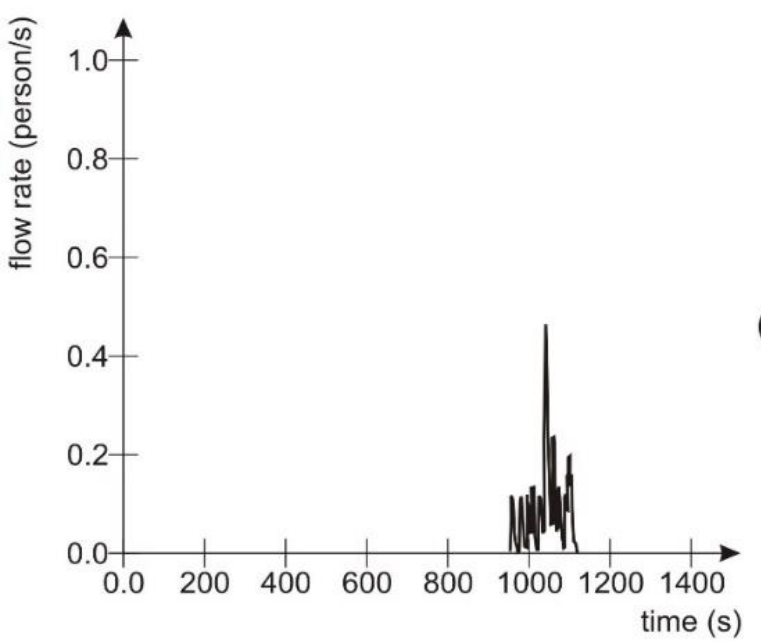

(b)

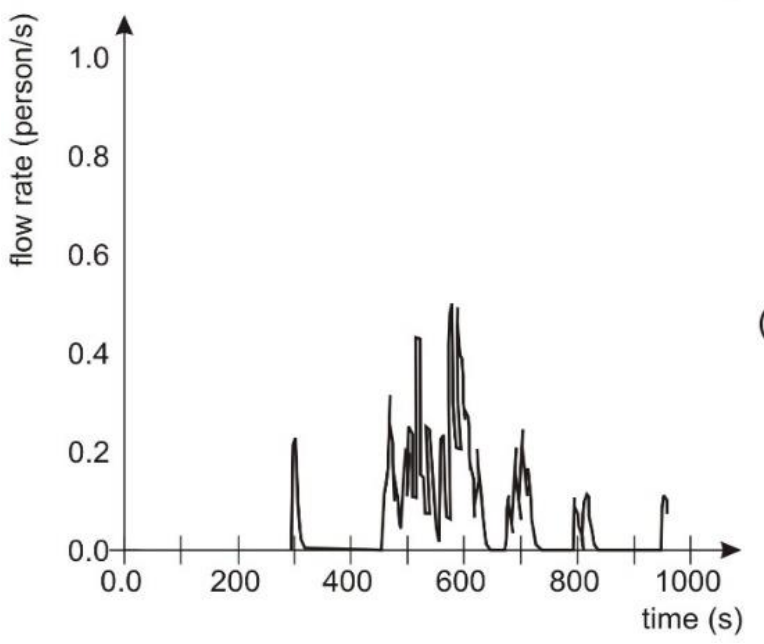

Figure 5. Flow rate (person/s) over time through exit F18 for: (a) first scenario (fire in the electrical room); (b) second scenario (fire in the kitchen room); (c) third scenario (fire in the patient's room)

The figure shows the trend related to the first scenario, for which a peak of 10 person in $8 \mathrm{~m}^{2}$ (the "smoke proof filter") generates a bottleneck that prevents other patients from exiting the ward. Actually, this overcrowded area, although built according to the Italian fire department regulation and built to prevent the spreading of smokes from the two adjacent wards, is too small to easily hold people and beds (which are $2.20 \mathrm{~m}$ long), allowing the opening of a door too. People are trapped in this space, unless someone else keep the two doors open simplifying the movement of beds; but keeping both doors 
open would neutralize the effect of the filter because smoke would not be stopped. The request of Italian fire protection laws seems actually not so appropriate because it generates a bottleneck, perfectly visible from the simulations. Moreover, some nurses still need to enter the threatened ward to move patient to the safe one, and they further prevent the egress. The situation in the area, 1551 seconds after the beginning, is shown in the picture of $6 \mathrm{~b}$.
With regard to the second scenario, there are not instances of overcrowding. The smoke proof filter, preceding the exit $\mathrm{F} 30$, is $18 \mathrm{~m}^{2}$ large; the maximum number of persons simultaneously staying in this area is 8 . Also, with regard to the third scenario, the bottleneck occurs in the smoke proof filter, even if the number of bed-bound patients was lower than the previous simulation (just 6 instead of 10).

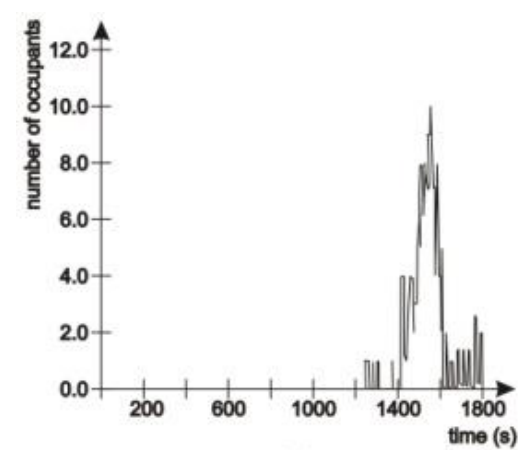

(a)

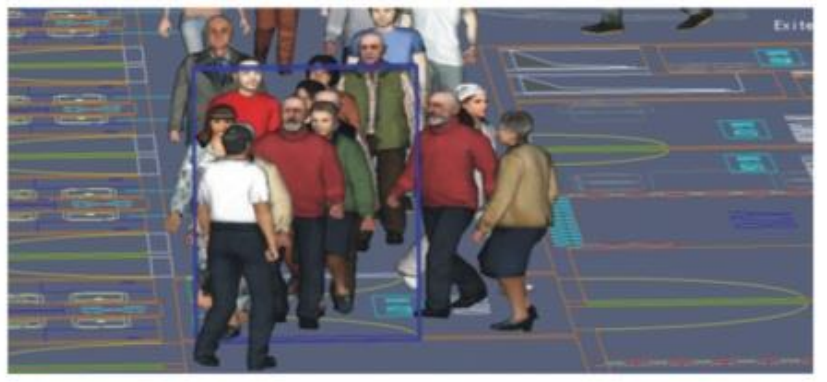

(b)

Figure 6. Number of occupants over time in the area in front of exit F18 in the first scenario (a), bottleneck at the exit F18 (square in blue) at the time $\mathrm{t}=1551 \mathrm{~s}(\mathrm{~b})$

\section{RESULTS OF THE FIRE DRILL}

In order to make a comparison with experimental results, a scheduled fire drill of the fourth floor of Campus Bio-Medico University Hospital of Rome was held on May 7 2014. The drill was conducted with the hospital working at its full capability and together with the staff of the National Fire Corps (NFC). The ward used for the simulated evacuation was empty and located at the fourth floor of the building, identical to the third floor. The fire is assumed to start in a patient room, located symmetrically to the room of the third scenario. Indeed, the goal of the evacuation drill was focused on the horizontal egress in the ward, with particular attention to the exit F18, and it required the staff to evacuate horizontally, without using the building's stairwells and elevators. The scheduled evacuation drill, for which volunteers acted as patients and instead nurses, doctors and other staff were real, provided the opportunity for us to collect egress data to compare with the outputs of the software. In Figure 7, staff and volunteers are shown during the fire drill together with the firefighters.

At time $\mathrm{t}=0$ the occupants of the ward were 1 deputy Head Nurse, 4 nurses, 4 nurse students, an attendant to the internal transports, 1 auxiliary, 10 doctors and postgraduates, 35 patients and 17 visitors. Each patient received a badge, which reported the disease and he performed a coherent behaviour; more specifically, they impersonated 5 bedridden patients and 30 independent ones. A fog machine had been placed in the room, generating white smoke that gradually spread in the ward, lowering the visibility. This action had not been accounted in the software simulation, that run under the hypothesis that visibility in the ward remains at less $10 \mathrm{~m}$ during the whole egress. We used two methods to collect data during the evacuation drill to provide occupancy and flow data: video, to disseminate journey times, and manual counts. The survey team was provided with video from internal security cameras. These cameras were placed close to the ceiling in order to capture a top-down view of people as they traversed the stairs thereby allowing the study team to track movements and behaviours. A digital video camera was set up to capture behaviour and movements during the evacuation. Manual counts were taken at the internal exits of the ward. Counters were directed to stand out of the way of those evacuating so as not to interfere with the flows. Each counter took note of the number of people exiting the main door.

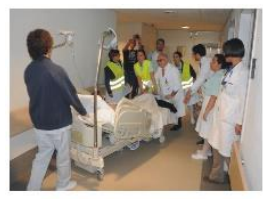

(a)

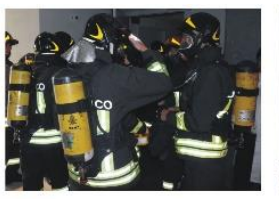

(b)

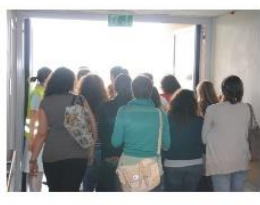

(c)
Figure 7. Fire drill (fire in the patient's room): (a) volunteers and medical staff; (b) firefighters enter the ward; (c) flow through exit F4

In order to prevent accidents, according to the request of the local NFC, not all exits were available and real patients and actors had to use different exits and routes to exit the ward. For example, four postgraduates accompanied the visitors towards the outside stairs, whereas some autonomous patients were accompanied towards the outdoor gathering place and others towards the contiguous ward, together with the bedridden patients. A total of 76 persons were observed evacuating during the drill; 56 used stairway and 16 went in the adjacent ward. Video recorded during the evacuation drill was used to calculate observed flow rates through exit doors and in smoke proof filter and total egress time, which was then compared to modelled egress time. Some discrepancies between modelled and observed flows were found, for example regarding the evacuation time. The observed evacuation time was 860 seconds, whereas that resulting from simulation was 957 seconds. It may be partially explained by the uncertain and therefore inaccurate replication of pre-movement time and by the slightly differences in the speed of patients (old in the model, young in the real drill as they were students). Profiles 
of occupants that is more accurate can be performed, in order to simulate behaviour of occupants that is more realistic.

\section{CONCLUSIONS}

In this work, a simulation software, together with an evacuation drill, has been used in order to identify the problems that arise in the egress from a hospital ward. Results indicate that computer simulations are suitable applications for egress modelling, producing total evacuation times similar to those observed during fire drill. Actually, the real drill took less time, probably because people were aware of the drill and people who took part were younger and faster than modelled geriatric inpatients. More accurate model for pre-movement time can be obtained by experimental results. Additionally, agent movements and behaviours through doors corresponded well to observations. Simulations can be used to test egress and evacuation scenarios and to make recommendations for safety preparedness improvements. They can be used to teach people what they should do in case of fire, which exit they can use, which sequence of actions they must follow. In addition, the computer simulation can point out some critical points of the procedures, or of the building configuration, although conforming to the laws in force. As for the software itself, it could get better with some improvements. More drawing tools (similar at those found in the most common drawing software, for instance AutoCAD) could be added. In addition, it could be useful the chance of varying some features, as time passes by (for instance nurses are slower when guiding a bed bound or a patient who needs assistance toward an exit and faster when moving alone in the corridor). On the other hand, the realistic fire drill remains a very useful tool in order to show several critical points. For example, although the emergency lighting in the ward is conform to rules according with the laws in force, it has been shown that in presence of smoke it does not ensure adequate visibility; this will be taken into account in the design of appropriate safety measures.

\section{ACKNOWLEDGMENT}

Authors thank the staff of Campus Bio-Medico University Hospital of Rome for their help in producing the evacuation drill, the staff of the third ward for enabling us to visit the ward to observe their daily operations, the staff of The National Fire Corps for the valuable support offered in the planning and realizing of the evacuation drill.

\section{FUNDING}

This research did not receive any specific grant from funding agencies in the public, commercial, or not-for-profit sectors.

\section{REFERENCES}

[1] O'Connor, D.J. (2005). Integrating human behaviour factors into design. Journal of Fire Protection Engineering, 28: 8-20.

[2] Bryan, J.L. (2002). A selected historical review of human behavior in fire. Journal of Fire Protection Engineering,
16: 4-10.

[3] Tong, D., Canter, D. (1985). The decision to evacuate: A study of the motivations which contribute to evacuation in the event of fire. Fire Safety Journal, 9(3): 257-265. http://dx.doi.org/10.1016/0379-7112(85)90036-0

[4] Sime, J.D. (1999). An occupant response shelter escape time (ORSET), model: Research and practice. in: Fire and Explosions: Recent Advances in Modelling and Analysis, Professional Engineering Publishing Ltd., London, Bury St. Edmunds, pp. 23-33.

[5] Sime, J.D. (2001). An occupant response shelter escape time (ORSET) model. Safety Science, 38(2): 109-125. http://dx.doi.org/10.1016/S0925-7535(00)00062-X

[6] He, G.Q., Yang, Y., Chen, Z.H., Gu, C.H., Pan, Z.G. (2013). A review of behavior mechanisms and crowd evacuation animation in emergency exercises. Journal of Zhejiang University-SCIENCE C (Computers \& Electronics), 14(7): 477-485. http://dx.doi.org/10.1631/jzus.CIDE1301

[7] Koo, J., Kim, B., Kim, Y.S. (2014). Estimating the effects of mental disorientation and physical fatigue in a semi-panic evacuation. Expert Systems with Applications, 41(5): 2379-2390. http://dx.doi.org/10.1016/j.eswa.2013.09.036

[8] Kobes, M., Helsloot, I., Vries, B., Post, J.G. (2010). Building safety and human behavior in fire: A literature review. Fire Safety Journal, 45(1): 1-11. https://doi.org/10.1016/j.firesaf.2009.08.005

[9] Silva, J.F., Almeida, J.E., Rossetti, R.J.F., Le Coelho, A. (2013). A Serious Game for EVAcuation Training. IEEE 2nd International Conference on Serious Games and Applications for Health. http://dx.doi.org/10.1109/SeGAH.2013.6665302

[10] Meng, F., Zhang, W. (2014). Way-finding during a fire emergency: An experimental study in a virtual environment. Ergonomics, 57(6): 816-827. http://dx.doi.org/10.1080/00140139.2014.904006

[11] Kuligowski, E. (2013). Predicting human behavior during fires. Fire Technology, 49(1): 101-120. http://dx.doi.org/10.1007/s10694-011-0245-6

[12] Jiang, M., Zhang, P., Shang, R., Tian, X. (2014). Investigation and simulation on human evacuation behaviour in large hospital building in Shenyang. Procedia Engineering, 71: 101-106.

[13] Tayfur, E., Taaffe, K. (2009). A model for allocating resources during hospital evacuations. Computers \& Industrial Engineering, 57: 1313-1323.

[14] Golmohammadi, D., Shimshak D. (2011). Estimation of the evacuation time in an emergency situation in hospitals. Computers \& Industrial Engineering, 61(4): 1256-1267. http://dx.doi.org/10.1016/j.cie.2011.07.018

[15] Koo, J., Kim, Y.S., Kim, B., Christensen, K.M. (2013). A comparative study of evacuation strategies for people with disabilities in high-rise building evacuation. Expert Systems with Applications, 40(2): 406-417. http://dx.doi.org/10.1016/j.eswa.2012.07.017

[16] Viswanathan, V., Lee, C.E., Lees, M.H., Cheong, S.A., Sloot, P.M.A. (2014). Quantitative comparison between crowd models for evacuation planning and evaluation. Euro Physics Journal B, 87: 27. http://dx.doi.org/10.1140/epjb/e2014-40699-X

[17] Li, W.H., Zhu, J.L., Li, H.Y., Wu, Q., Zhang, L. (2015). A game theory based on monte Carlo analysis for optimizing evacuation routing in complex scenes. 
Mathematical Problems in Engineering, 292093, 11 pages. http://dx.doi.org/10.1155/2015/292093

[18] Bi, H.B., Gelenbe, E. (2019). A survey of algorithms and systems for evacuating people in confined spaces. Electronics, $8(6)$ : 711-738. https://doi.org/10.3390/electronics8060711

[19] Kuligowski, E.D., Peacock, R., Hoskins, B.L. (2010). A review of building Evacuation Models NIST Technical Note, 1680

[20] Di Nenno, P.J. (2002). SFPE Handbook of Fire Protection Engineering, Society of Fire Protection Engineers, National Fire Protection Association, Batterymarch Park Quincy.

[21] Thunderhead engineering (2013). Pathfinder: Technical Reference, Manhattan, 1-44.

[22] Decree of the Minister of the Interior 18 September 2002, Approval of the technical rule on fire prevention for the design, construction and operation of public health facilities and private (in Italian language) Approvazione della regola tecnica di prevenzione incendi per la progettazione, costruzione ed esercizio delle strutture sanitarie pubbliche e private, 2002

[23] Decree of the Minister of the Interior 19 March 2015, Updating of the technical rule on fire prevention for the design, construction and operation of public and private health facilities in the Decree of the Minister of the
Interior September 18, 2002 (in italian language) Aggiornamento della regola tecnica di prevenzione incendi per la progettazione, la costruzione e l'esercizio delle strutture sanitarie pubbliche e private di cui al decreto del Ministro dell'interno 18 settembre 2002, 2015

[24] Lovreglio, R., Ronchi, E., Nilsson, D. (2016). An Evacuation Decision Model based on perceived risk, social influence and behavioural uncertainty. Simulation Modelling Practice and Theory, 66: 226-242. http://dx.doi.org/10.1016/j.simpat.2016.03.006

[25] Schadschneider, A., Klingsch, W., Klüpfel, H., Kretz, T., Rogsch, C., Seyfried, A. (2009). Evacuation dynamics: Empirical results, modeling and applications. Encyclopedia of Complexity and Systems Science, 31423176. http://dx.doi.org/10.1007/978-0-387-30440-3_187

[26] Chraibi, M., Tordeux, A., Schadschneider, A., Seyfried, A. (2018). Modelling of pedestrian and evacuation dynamics. Encyclopedia of Complexity and Systems Science, 1-22.

[27] Rahouti, A., Lovreglio, R., Jackson, P. and Datoussaïd, S. (2018). Evacuation Data from a Hospital Outpatient Drill the Case Study of North Shore Hospital, 9th conference on Pedestrian and Evacuation Dynamics.

[28] Rahouti, A., Lovreglio, R., Dias, S. and Datoussaï, S. (2017). Simulating Assisted Evacuation using Unity3D. Traffic \& Granular Flow. 